\title{
Research on large-scale wind power utilization technology based on energy storage
}

\author{
Xiaochen Zhang ${ }^{1,2^{*}}$, Wei $\mathrm{Du}^{1,2}$, Jinzhou $\mathrm{Fu}^{1,2}$, Dongmei Yang ${ }^{1,2}$, Yonghua Chen ${ }^{1,2}$ \\ ${ }^{1}$ NARI Group Corporation(State Grid Electric Power Research Institute), 211106 Nanjing, China \\ ${ }^{2}$ NARI Technology Co., Ltd., 211106 Nanjing, China
}

\begin{abstract}
To improve the wind power utilization, methods of adding electricity storage device, adding heat storage device, treating the heat pipe network as a heat storage device are proposed. Firstly, the characteristics of cogeneration, electricity storage and heat storage equipment are analyzed. Secondly, the objective function of thermoelectric system is constructed. Meanwhile, system constraints are also introduced. Then, the scheduling model is transformed into a linear programming problem and solved with CPLEX toolbox. Finally, a typical cogeneration case is established to test the effectiveness of the proposed methods. The simulation results show that all these methods can effectively improve the amount of wind power utilization.
\end{abstract}

\section{Introduction}

Climate change issues such as energy crisis and global warming promote the transformation of electric energy from structural reduction of fossil energy consumption to large-scale utilization of clean energy [1-3]. The continuous increase of renewable energy penetration will bring far-reaching impacts and challenges to grid operation. Along with the increasing scale of wind power installation and grid connection, China's northeast, northwest face severe wind power abandonment. In these areas, the power supply is mainly based on cogeneration units, and the peak-shaving capability is lacking. Usually, the operation mode of "electricity power based on heat" is adopted. When the heat supply is preferentially satisfied during the heating supply period, the adjustable range of electricity generation output is limited. Increased the lack of peaking ability of the system, resulting in severe wind power abandonment phenomenon[4-5].

In order to improve the ability of the cogeneration unit to participate in wind power utilization during the heating supply period, and get rid of the "electricity power based on heat" policy to restrict its operation mode, we can increase the energy storage as additional equipment to participate in the energy supply, so that the output heat power of the cogeneration unit does not have to be matching the heat load at all times. On the premise of ensuring the safe and stable operation of the power system, how to rationally increase the energy storage equipment, formulate the scientific economic dispatch of the thermoelectric system, improve the peak shaving capacity of the power system, and promote the consumption of wind power are the key issues to be solved.
The application of large-scale electricity storage technology is similar to the peak-shaving effect of pumped storage. When the wind power output is large and the electric load is low, the battery is charged, and when the electric load is high, the battery is discharged. At the same time, the configuration of large-capacity heat storage equipment in the thermoelectric system can break the rigid constraint of "electricity power based on heat", effectively improve the regulation capacity of the cogeneration unit, and increase the utilization of wind power [6-8]. In this paper, the characteristics of cogeneration, electricity storage and heat storage equipment are analyzed, then the wind power utilization model of thermoelectric system operation is constructed. The model is summarized into a linear programming problem and solved. Finally, different modes are analyzed. The amount of wind power consumption proves the effectiveness of the proposed method for improving wind power utilization.

\section{Mathematical model of thermoelectric system}

\subsection{Thermoelectric system}

In northern China, the cogeneration unit is used in large quantities because of its characteristics of both heat supply and electricity power generation [9-10]. This also causes the power generation of the cogeneration unit to occupy the main part of the conventional power supply during the heating supply period. In the traditional thermoelectric system, the cogeneration unit and wind turbine can provide electric energy. The gas boiler and the cogeneration unit provide thermal energy by using 
fossil fuel. In the system, the output thermal power of the cogeneration unit is proportional to the output electric power. The system is less flexible. A typical cogeneration power plant without energy storage equipment is shown in Figure 1.

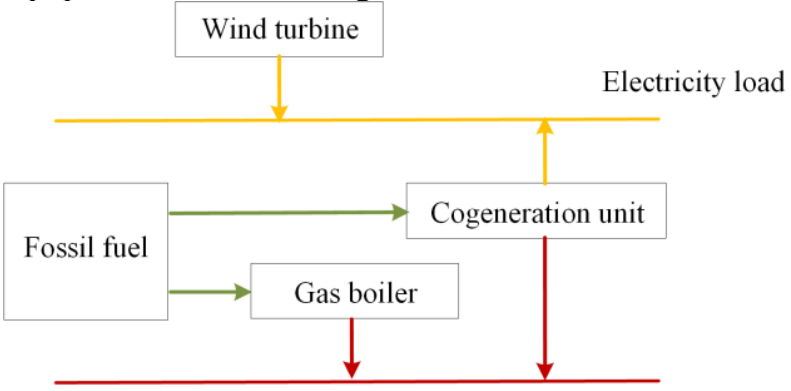

Thermal load

Fig. 1. Structure of a typical cogeneration power plant.

\subsection{Mathematical model}

\subsubsection{Cogeneration unit}

Cogeneration unit can produce electricity and provide heat to users. There is a coupling relationship between external heating power and output electricity power. The main constraints of cogeneration unit include:

1)Thermoelectric ratio constraint:

$$
P_{c h p}=\frac{P_{h c h p}}{k_{c h p}}
$$

where $P_{c h p}$ and $P_{h c h p}$ are electricity power and heat power, respectively. $k_{c h p}$ is the proportionality coefficient.

2)Unit climbing rate constraint:

$$
-D_{R, \max } \cdot \Delta t \leq \Delta P_{c h p} \leq U_{R, \text { max }} \cdot \Delta t
$$

where $\Delta P_{c h p}$ is the power change rate of the cogeneration unit. $D_{R, \max }$ and $U_{R, \max }$ are down and up power change limits.

\subsubsection{Wind turbine}

The output power of wind turbine is a piecewise function relationship with the meteorological conditions. The wind turbine output power are as follows:

$$
\begin{gathered}
\underline{P}_{\text {wind }} \leq P_{\text {wind }} \leq \bar{P}_{\text {wind }} \\
\bar{P}_{\text {wind }}= \begin{cases}\frac{v-v_{\text {in }}}{v_{\text {rate }}-v_{\text {in }}} P_{\text {rate }} & v_{\text {in }} \leq v \leq v_{\text {rate }} \\
P_{\text {rate }} & v_{\text {rate }}<v \leq v_{\text {out }}\end{cases}
\end{gathered}
$$

where $\underline{P}_{\text {wind }}, P_{\text {wind }}$ and $\bar{P}_{\text {wind }}$ are the output power lower limit, output power and output power upper limit of the wind turbine, respectively. $v$ is the current wind speed, $v_{\text {rate }}$ is the rated wind speed. $v_{\text {in }}$ and $v_{\text {out }}$ are cut-in wind speed and cut-out wind speed, respectively.

\subsubsection{Electricity storage}

The battery power includes two processes. For charging process, the battery power is as follows:

$$
S_{t+1}=S_{t}(1-\varepsilon)+P_{c} \eta_{c}
$$

where $S_{t+l}$ and $S_{t}$ are the dump energy, $\varepsilon$ is the electricity leakage rate. $P_{c}$ is charging power and $\eta_{c}$ is charging efficiency.

For discharging process, the battery power is as follows:

$$
S_{t+1}=S_{t}(1-\varepsilon)-P_{d} \eta_{d}
$$

where $P_{d}$ is the discharging power, $\eta_{d}$ is the discharging efficiency.

\subsubsection{Heat storage}

The heat storage capacity cannot exceed the maximum heat storage capacity of the heat storage device.

$$
0 \leq E_{h, t} \leq E_{h, \text { max }}
$$

where $E_{h, t}$ is the heat storage capacity, $E_{h, \max }$ is the maximum heat storage capacity of the heat storage device.

The heat storage power $P_{h i n, t}$ and heat release power $P_{\text {hout }, t}$ of the heat storage device are limited by the heat exchanger.

$$
\begin{gathered}
0 \leq P_{\text {hin,t }} \leq P_{\text {hin,max }} \\
0 \leq P_{\text {hout }, t} \leq P_{\text {hout,max }}
\end{gathered}
$$

where $P_{\text {hin,max }}$ and $P_{\text {hout,max }}$ are the maximum power of the heat exchanger.

\section{Optimal dispatching of thermoelectric system}

\subsection{Objective function}

In the thermoelectric system, the objective function is to minimize the quantity of wind power abandon [11-12]. The objective function is as follows:

$$
\min \sum_{i=1}^{N t} \sum_{j=1}^{N w} P_{i, j}
$$

where $N_{t}$ is the period of one day, $N_{w}$ is the number of the wind farm, $P_{i, j}$ is the amount of wind power abandon.

\subsection{System constraints}

The electricity generation and consumption in thermoelectric system should keep balance at all times:

$$
P_{D G}+P_{c o}+P_{\text {stor }}=P_{\text {load }}
$$

where $P_{D G}$ is the distributed generation power, $P_{c o}$ is the electricity power of cogeneration unit, $P_{\text {stor }}$ is the power of electricity storage. $P_{\text {load }}$ is the electricity load.

The heat generation should meet the heat demand at all times:

$$
H_{c o}+H_{\text {stor }}+H_{\text {boiler }} \geq H_{\text {load }}
$$


where $H_{c o}$ is the heat power of cogeneration unit, $H_{\text {stor }}$ is the power of heat storage, $H_{\text {boiler }}$ is the power of gas boiler, $H_{\text {load }}$ is the heat load.

During the whole dispatching period, the sum of the stored energy and the released energy should be equal.

$$
\sum_{t_{\text {cha }}} \Delta W\left(t_{\text {cha }}\right)=\sum_{t_{\text {discha }}} \Delta W\left(t_{\text {discha }}\right)
$$

where $\Delta W\left(t_{c h a}\right)$ is the charge amount and $\Delta W\left(t_{\text {discha }}\right)$ is the discharge amount.

\section{Dispatching model and solution}

The scheduling model of wind power utilization is an optimization problem with complex equality constraints and inequality constraints. The standard form of wind power utilization optimization model is as follows:

$$
\left\{\begin{aligned}
& \min \sum_{i=1}^{N t} \sum_{j=1}^{N w} P_{i, j} \\
& \text { s.t. } \quad \mathbf{A}_{1} \mathbf{X}=\mathbf{B}_{1} \\
& \mathbf{A}_{2} \mathbf{X} \leq \mathbf{B}_{2} \\
& x_{i, \min } \leq x_{i} \leq x_{i, \max }
\end{aligned}\right.
$$

where $P_{i, j}$ is the amount of wind power abandon as is explained in formula (10), $\mathbf{X}$ are the variables to be scheduled. $\mathbf{A}_{1}$ and $\mathbf{B}_{1}$ are the equality constraint coefficients. $\mathbf{A}_{2}$ and $\mathbf{B}_{2}$ are the inequality constraint coefficients. $x_{i, \min }$ and $x_{i, \max }$ are the constraint intervals of variable.

For the above scheduling model, this paper transforms it into a linear programming problem and solves it in MATLAB with CPLEX toolbox.

\section{Case study}

\subsection{A typical cogeneration case}

This paper refers a typical cogeneration case. The structure of the case is shown in Figure 2. The case includes facilities such as wind turbine, cogeneration unit, gas boiler.

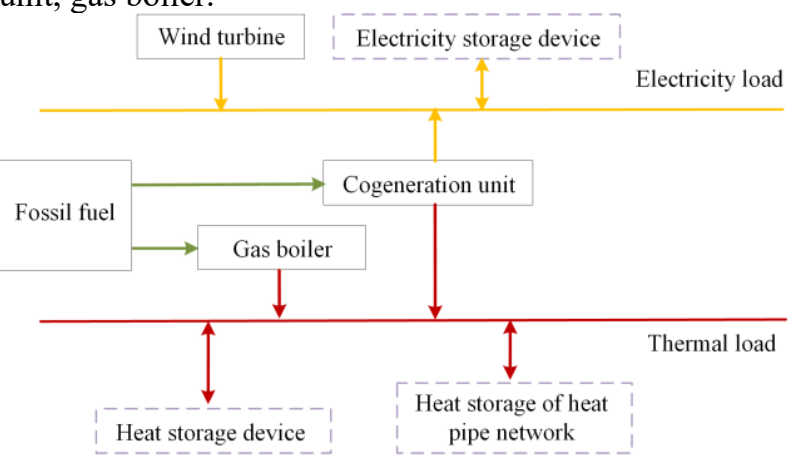

Fig. 2. Structure of a typical cogeneration case.

The wind power utilization scheduling period is 24 hours, and the scheduling interval is 1 hour. The case contains both electricity load and heat load requirements. Figure 3 shows the load curves.

The main devices' parameters are shown in Table 1. The electricity and heat proportion of cogeneration unit is 1.35. For the electricity storage device and heat storage device, the state of charge (SOC) is 0.2 to 0.8 . Figure 4 shows the power generation of the wind turbine. To improve the wind power utilization, this paper discuss three kinds of methods, such as adding electricity storage device, adding heat storage device, treating the heat pipe network as a heat storage device.

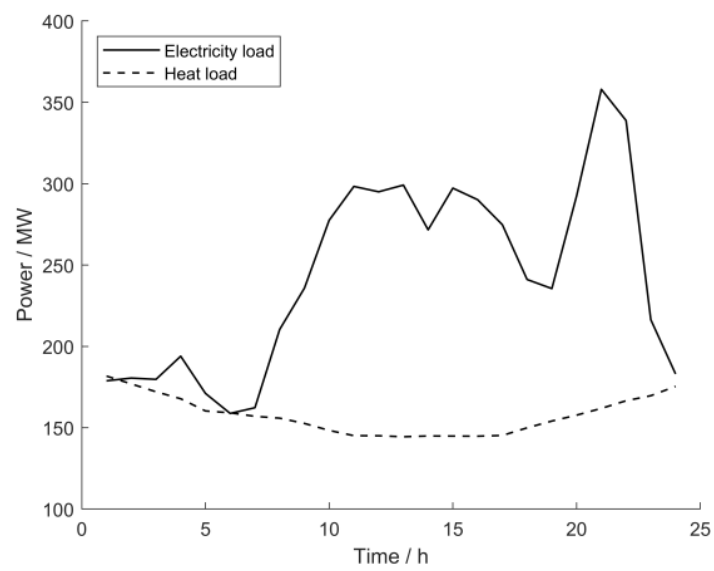

Fig. 3. Load curves of electricity and heat.

Table 1. Device parameters.

\begin{tabular}{|c|c|c|}
\hline Device & $\begin{array}{c}\text { Lower limit of } \\
\text { output / MW }\end{array}$ & $\begin{array}{c}\text { Upper limit of } \\
\text { output / MW }\end{array}$ \\
\hline $\begin{array}{c}\text { wind power } \\
\text { utilization }\end{array}$ & 0 & 285 \\
\hline $\begin{array}{c}\text { cogeneration unit } \\
\text { (electricity) }\end{array}$ & 30 & 50 \\
\hline gas boiler & 0 & 50 \\
\hline $\begin{array}{c}\text { electricity storage } \\
\text { device }\end{array}$ & -50 & 50 \\
\hline heat storage device & -50 & 50 \\
\hline
\end{tabular}

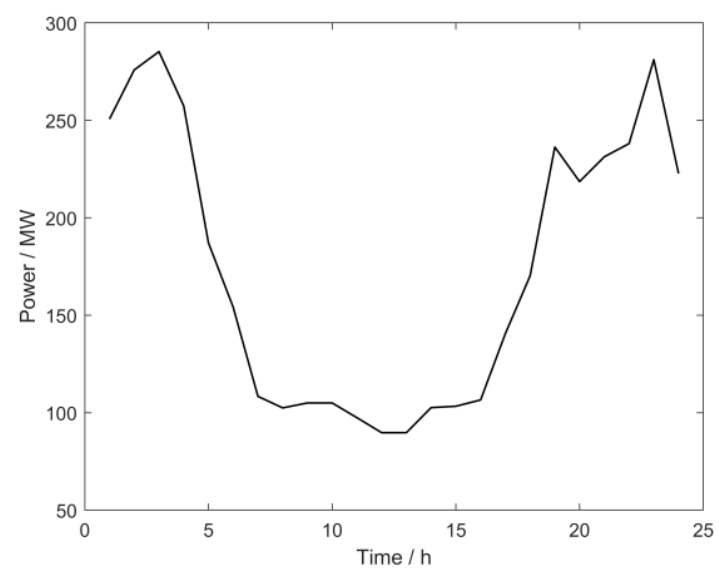

Fig. 4. Wind turbine power generation. 


\subsection{Results and discussion}

To analyze the effect of three methods mentioned in this paper on increasing wind power utilization, the following five scenarios are discussed in this section:

(1) The basic scenario

This scenario calculates the output power of each device without electricity storage or heat storage. Figure 5 shows output power of the equipment. And Figure 6 shows the wind power utilization in this scenario.

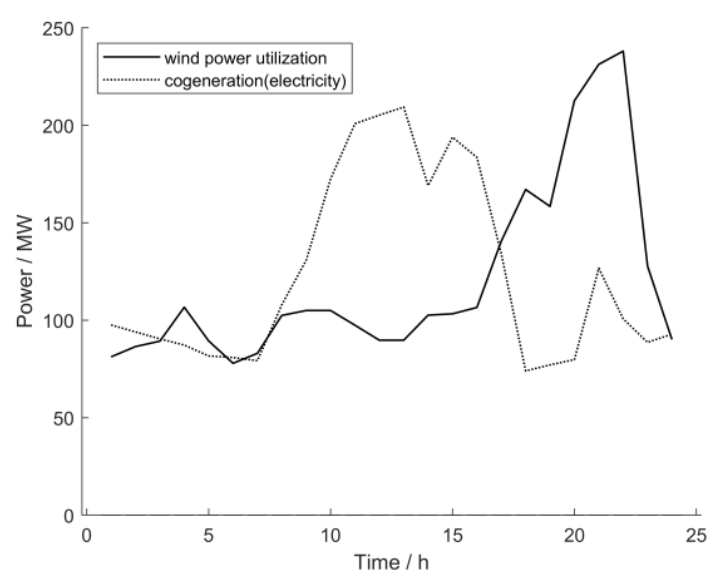

Fig. 5. Output power of the equipment.

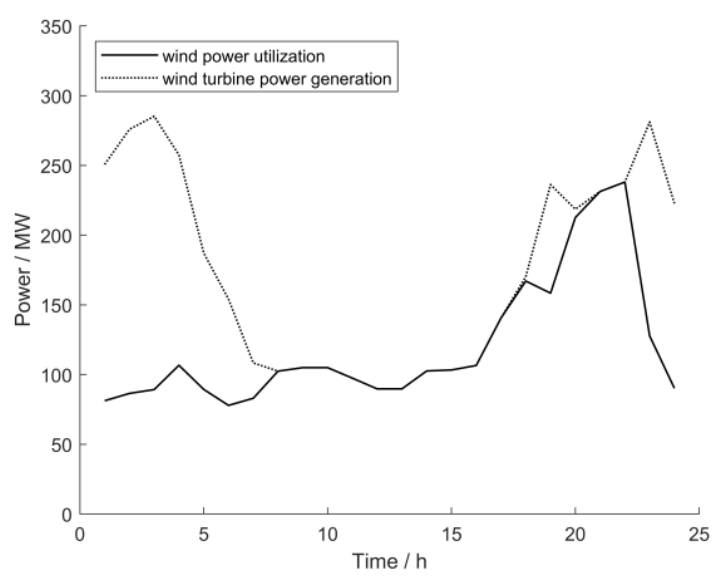

Fig. 6. Wind power utilization.

(2) The basic scenario with electricity storage

An electricity storage is added based on scenario 1 , and the output power of the equipment is shown in Figure 7 . The wind power utilization in this scenario is shown in Figure 8.

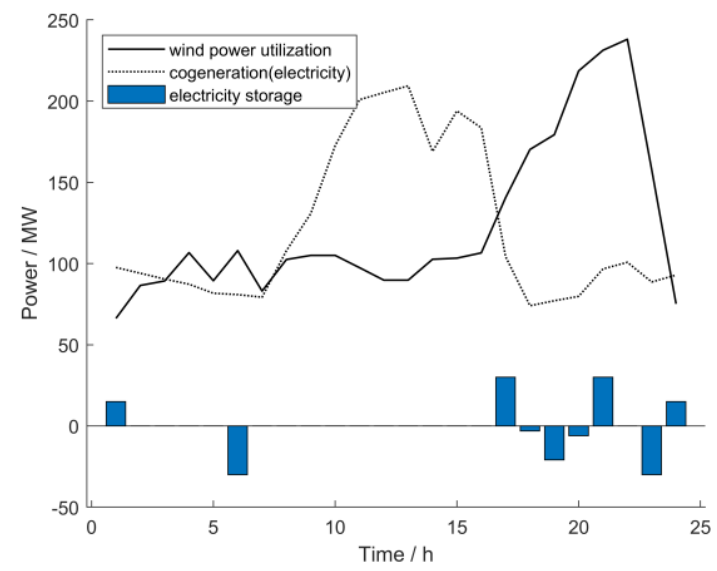

Fig. 7. Output power of the equipment.

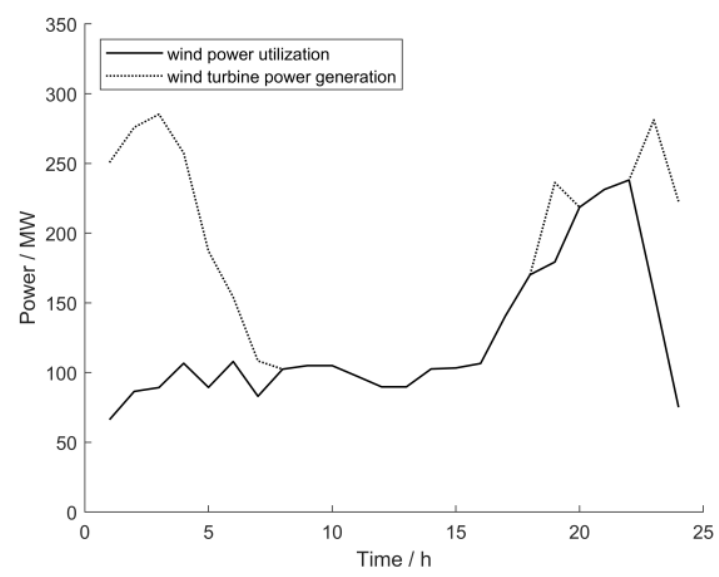

Fig. 8. Wind power utilization.

(3) The basic scenario with heat storage

A heat storage is added based on scenario 1, and the output power of the equipment is shown in Figure 9. The wind power utilization in this scenario is shown in Figure 10.

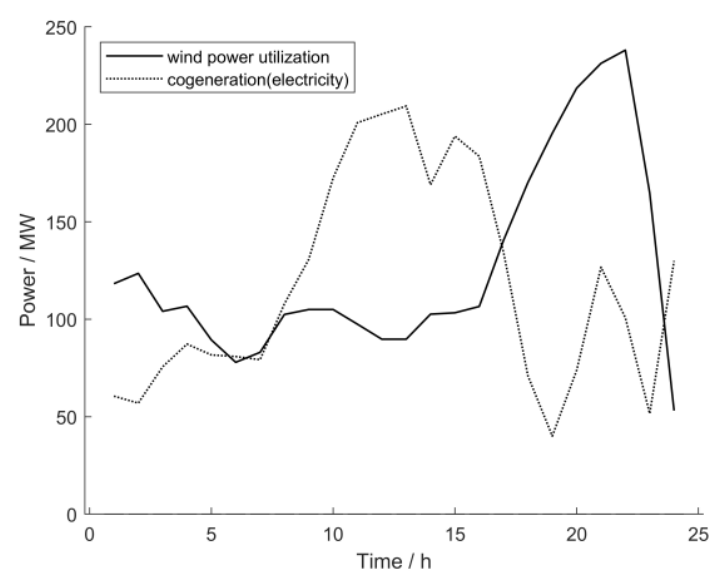

Fig. 9. Output power of the equipment. 


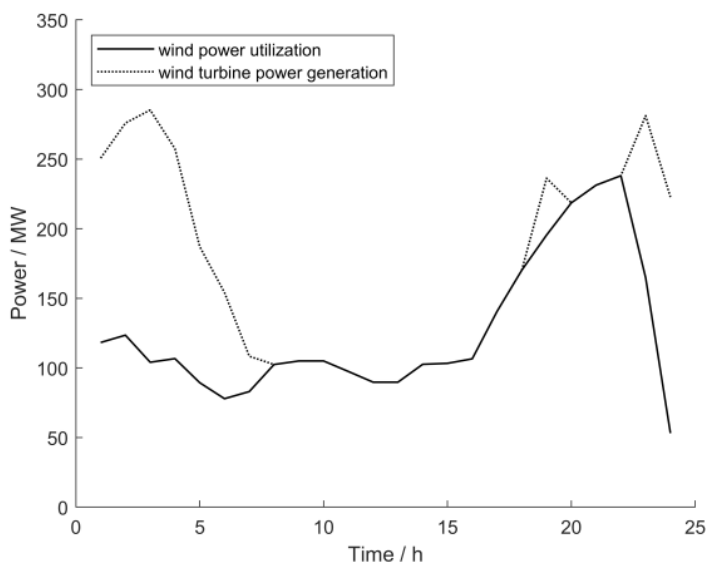

Fig. 10. Wind power utilization.

(4) The basic scenario with thermal delay scheduling

Since the heat pipe network can store a certain amount of heat, it can be regarded as a heat storage device [13-15]. Thus, it is necessary to ensure that the generated heat during a certain period of time is equal to the total heat load demand during the period. Therefore, this scenario calculates the effect of prolonging the thermal dispatch time on the amount of wind power consumption. When the heat dispatch time is extended from 1 hour to 4 hours, Figure 11 and Figure 12 show the calculated results.

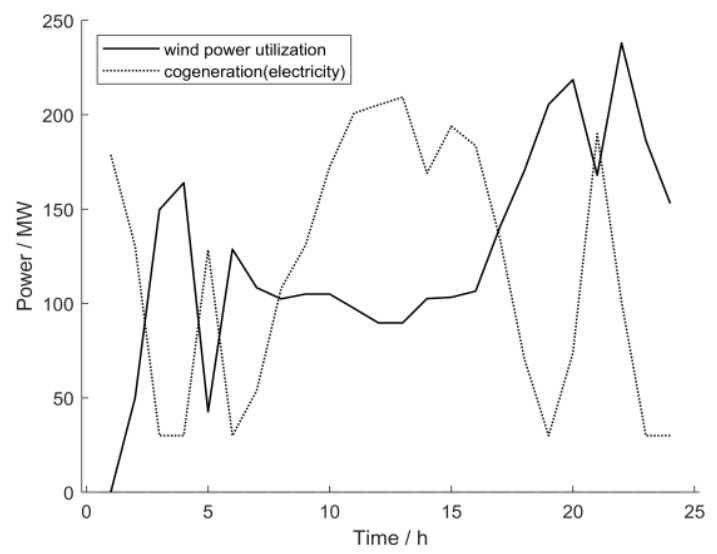

Fig. 11. Output power of the equipment.

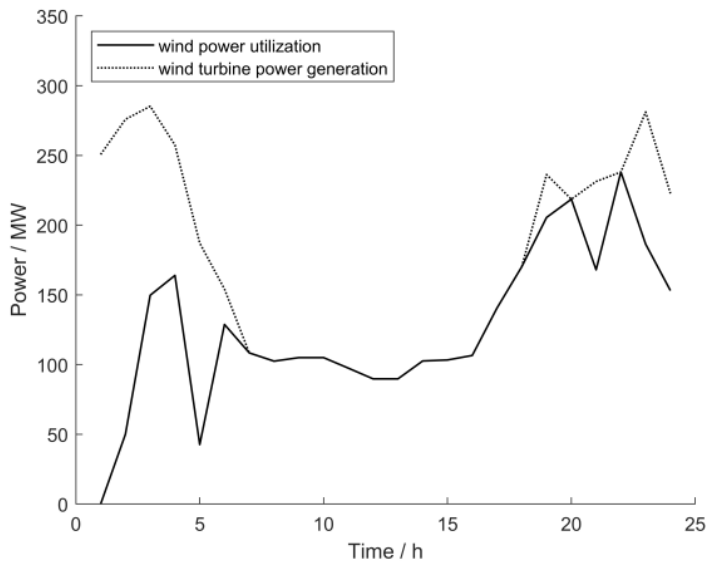

Fig. 12. Wind power utilization.
(5) The basic scenario with three methods

This scenario contains the electricity storage and heat storage. Meanwhile, the heat dispatch time is also extended from 1 hour to 4 hours. Figure 13 and Figure 14 show the calculated results.

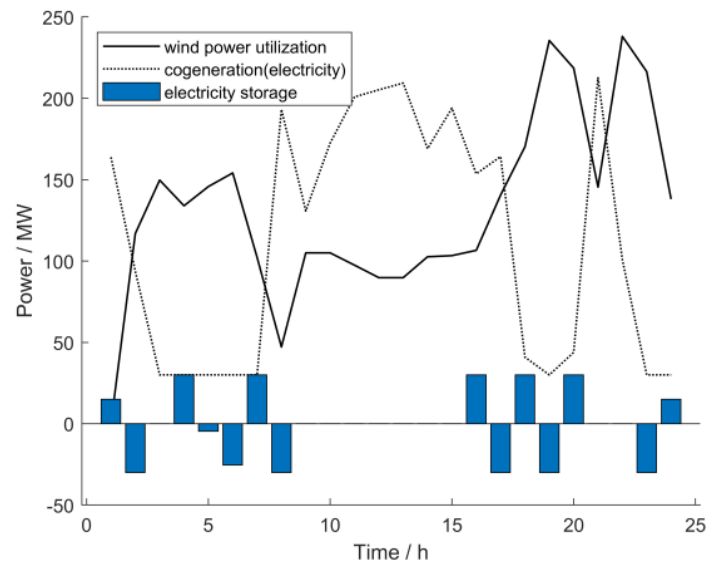

Fig. 13. Output power of the equipment.

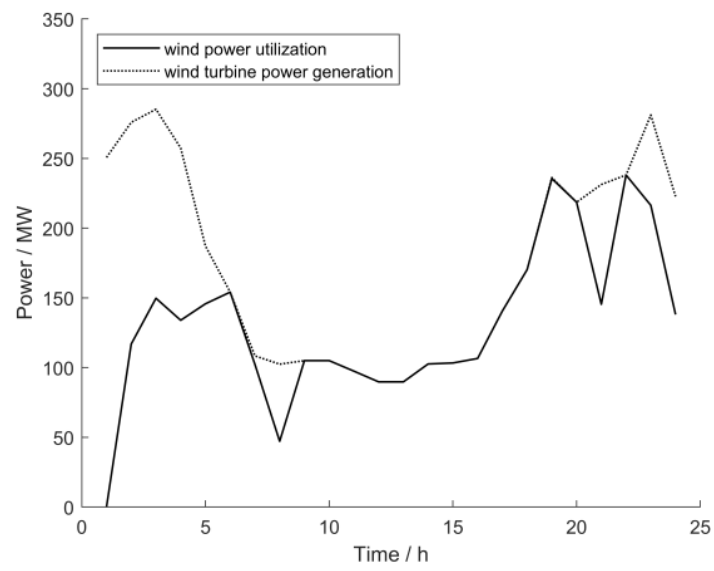

Fig. 14. Wind power utilization.

Table 2 shows the wind power utilization percentage under five scenarios. It is clear that three methods of adding electricity storage device, adding heat storage device, treating the heat pipe network as a heat storage device can effectively improve the wind power utilization. The basic scenario with three methods achieve the highest wind power utilization.

Table 2. Wind power utilization percentage.

\begin{tabular}{|c|c|c|}
\hline Scenario & $\begin{array}{c}\text { Wind power } \\
\text { utilization }\end{array}$ & $\begin{array}{c}\text { Increased percentage } \\
\text { (relative to the base } \\
\text { scenario) }\end{array}$ \\
\hline $\begin{array}{c}\text { The basic } \\
\text { scenario }\end{array}$ & $69.28 \%$ & - \\
\hline $\begin{array}{c}\text { with electricity } \\
\text { storage }\end{array}$ & $70.72 \%$ & $1.44 \%$ \\
\hline $\begin{array}{c}\text { with heat } \\
\text { storage }\end{array}$ & $72.53 \%$ & $3.25 \%$ \\
\hline $\begin{array}{c}\text { with thermal } \\
\text { delay scheduling }\end{array}$ & $72.74 \%$ & $3.46 \%$ \\
\hline
\end{tabular}




\begin{tabular}{|c|c|c|}
\hline $\begin{array}{c}\text { with three } \\
\text { methods }\end{array}$ & $75.78 \%$ & $6.5 \%$ \\
\hline
\end{tabular}

\section{Conclusion}

In this paper, the characteristics of cogeneration, electricity storage and heat storage equipment are analyzed, then the wind power utilization model of thermoelectric system operation is constructed. To improve the wind power utilization, methods of adding electricity storage device, adding heat storage device, treating the heat pipe network as a heat storage device are proposed. The calculation results show that all these methods can effectively improve the amount of wind power utilization.

The research is supported by the Science and Technology Project of SGCC (Research on optimal configuration and control strategy of energy storage power station for power grid).

\section{References}

1. H.B. Sun, Q.L. Guo, Z.G. Pan, et al. Energy internet: concept,architecture and frontier outlook[J]. Automation of Electric Power Systems, 2015,39(19):1-8.

2. Y.H. Cheng, N. Zhang, C.Q. Kang, et al. Research framework and prospects of low-carbon multiple energy systems[J]. Proceedings of the CSEE,2017,37(14):4060-4069.

3. A.H. Fathima, K. Palanisamy. Optimization in microgrids with hybrid energy systems-A review[J]. Renewable \& Sustainable Energy Reviews, 2015,45:431-446.

4. Z.R. Song, L. Zhao, Z.X. Zhang, et al. Rolling optimal model for multiple heating source and wind turbine unit[J]. Power System Protection and Control,2016,44(24) :110-116.

5. A. Christidis, C. Koch, L. Pottel, et al. The contribution of heat storage to the profitable operation of combined heat and power plants inliberalized electricity markets[J]. Energy,2012,37(1) :75-82.
6. H. Li, G.Y. Li, Y.W. Wu, et al. Operation Modeling of Power Systems Integrated with Large-Scale New Energy Power Sources[J]. Energies,2016,9(10):810.

7. Y.M. Atwa, E.F. El-Saadany, M.M.A. Salama, et al. Optimal Renewable Resources Mix for Distribution System Energy Loss Minimization[J]. IEEE Transactions on Power Systems,2010,25(1):360-370.

8. R.R. Zhai, Y. Chen, H.T. Liu, et al. Optimal Design Method of a Hybrid CSP-PV Plant Based on Genetic Algorithm Considering the Operation Strategy[J]. International Journal of Photoenergy,DOI : 10.1155/2018/8380276, 2018.

9. J.J. Li, L.X. Hu. Research on accommodation scheme of curtailed wind power based on peakshaving electric boiler in secondary heat supply network[J]. Power $\quad$ System Technology,2015,33(11) :3286-3291.

10. D. Xu, Q. Ding, G.D. Huang, et al. Cogeneration unit dynamic scheduling model considering peakload regulation ability[J]. Power System Protection and Control, 2017,45(11) :59-64.

11. A.B. Meng, P. Mei, H.M. Lu. Crisscross optimization algorithm for combined heat and power economic dispatch[J]. Power System Protection and Control, 2016,44(6): 90-97.

12. F. Levihn. CHP and Heat pumps to balance renewable power production :lessons from the district heating network in Stockholm[J]. Energy, 2017,42:670-678.

13. Y. Cui, Z. Chen, G.G. Yan, et al. Coordinated wind power accommodating dispatch model based on electric boiler and CHP with thermal energy storage $[\mathrm{J}]$. Proceedings of the CSEE, 2016,35(15):4072-4080.

14. H. Shabgard, M.J. Allen, N. Sharifi, et al. Heat pipe heat exchangers and heat sinks: Opportunities, challenges, applications, analysis, and state of the $\operatorname{art}[\mathrm{J}]$. International Journal of Heat and Mass Transfer, 2015,89:138-158.

15. H. Esen, M. Esen, O. Ozsolak. Modelling and experimental performance analysis of solar-assisted ground source heat pump system[J]. Journal of Experimental \& Theoretical Artificial Intelligence, 2017,29(1):1-17. 